\title{
Simultaneous Bilateral Femoral Neck Stress Fractures in a 24-year Old Male Recruit \\ A Case Report
}

O Nemoto, M Kawaguchi, T Katou

\section{INTRODUCTION}

Although several reports of femoral neck stress fracture in young military recruits have been published, bilateral femoral neck stress fractures occurring simultaneously is extremely rare. Since misdiagnosis of this condition and resulting error in treatment may lead to significant handicap, we have to bear the possibility of this fracture in mind. Here, we report a case of simultaneous bilateral femoral neck fractures in a 24-year old male recruit to the Japanese Ground Self Defense Force (JGSDF).

Keywords: Bilateral, femoral neck fracture, young adult

\section{CASE REPORT}

A 24-year old male college graduate and recruit to JGSDF began to have mild pain in his groins while running during the fourth week of basic training. His level of exercise was no different from his other colleagues. He was seen in the dispensary two days later for his pain, and a "charley horse" (muscle spasm) was diagnosed. Because of the increased pain and limping, he was referred to our clinic 10 days later and was immediately admitted to the hospital. He described an aching pain that was causing him to limp while walking. He denied sharp pain, numbness, tingling or any symptoms other than the aching pain. Past medical history, family history and social history were unremarkable.

On physical examination, he was $172 \mathrm{~cm}$ tall and weighed $63 \mathrm{~kg}$, with normal appearance. He was found to have an antalgic gait and moderate pain at the extremes of hip motion, especially at internal rotation. Strength was within normal limits, and the limb was neurovascularly intact distally.

Standard anteroposterior and axial views demonstrated a faint fracture on the right hip (Fig. 1), but on the left side a clear fracture line could be seen (Fig. 2). The magnetic resonance image (MRI) clearly revealed incomplete right and complete left femoral fractures with bone marrow oedema (Fig. 3). The results of laboratory blood work, which included a liver profile, electrocytes, a renal profile, and an alkaline phosphatase test, were normal.

From: Department of Orthopaedic Surgery, Japanese Self Defense Forces Central Hospital, 1-2-24, Ikejiri, Setagaya, Tokyo, Japan.

Correspondence: Dr O Nemoto, Department of Orthopaedic Surgery, Japanese Self Defense Forces Central Hospital, 1-2-24, Ikejiri, Setagaya, Tokyo, Japan. Fax: 03-5317-1766, e-mail: drsamusio@world.ocn.ne.jp

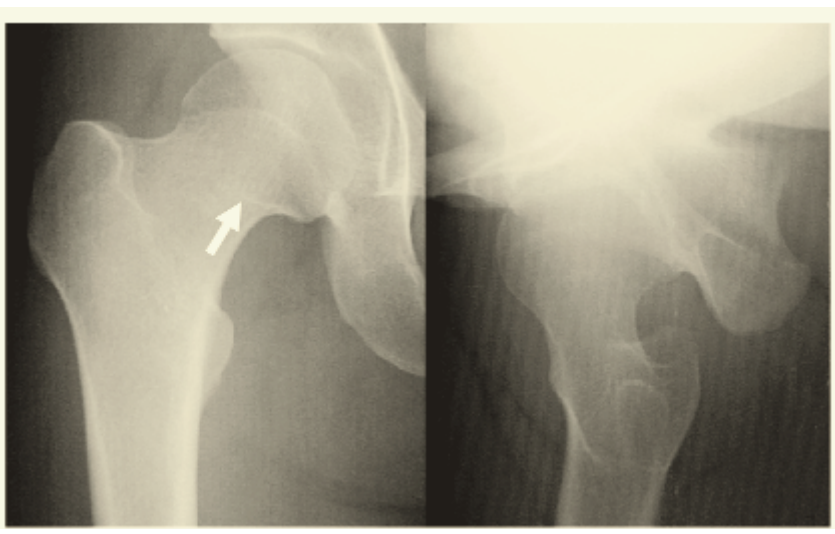

Fig. 1: A plain radiograph of the right hip demonstrating a faint fracture line (arrow).

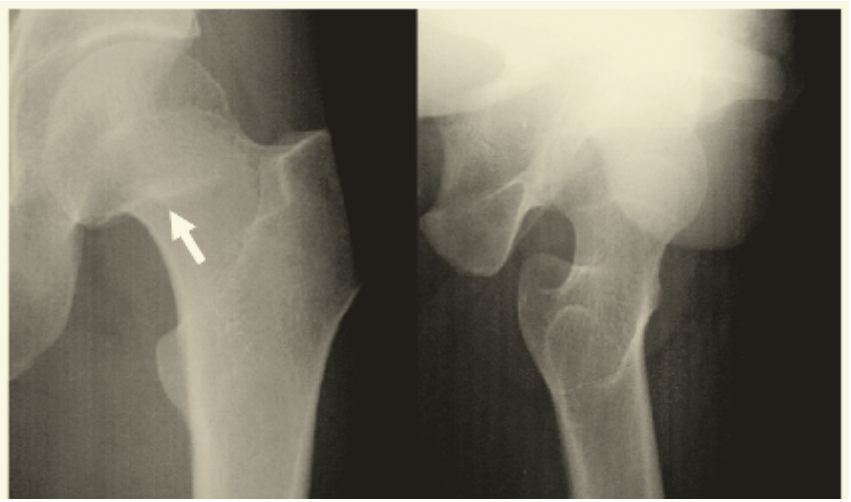

Fig. 2: A plain radiograph of the left hip demonstrating a clear fracture line (arrow).

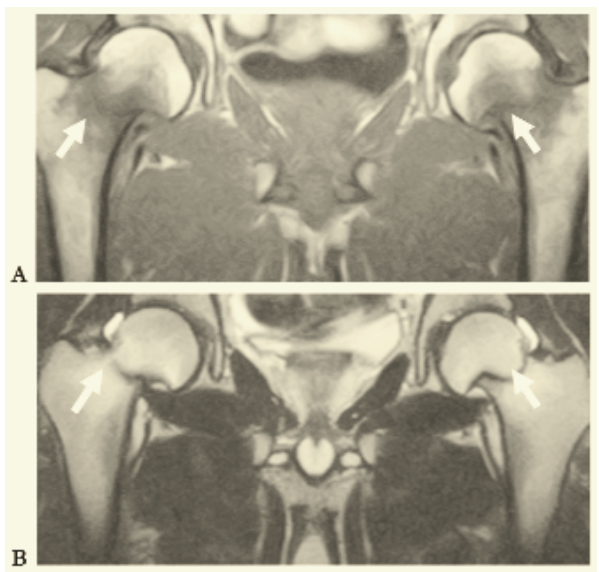

Fig. 3: A T2-weighted coronal magnetic resonance imaging (MRI) scan demonstrates an incomplete right and complete left fracture (B; arrows). Bone marrow oedema is clearly observed on T1-weighted image (A; arrows). 
The patient underwent surgery with internal fixation via cannulated screws (Fig. 4). Postoperatively, the patient

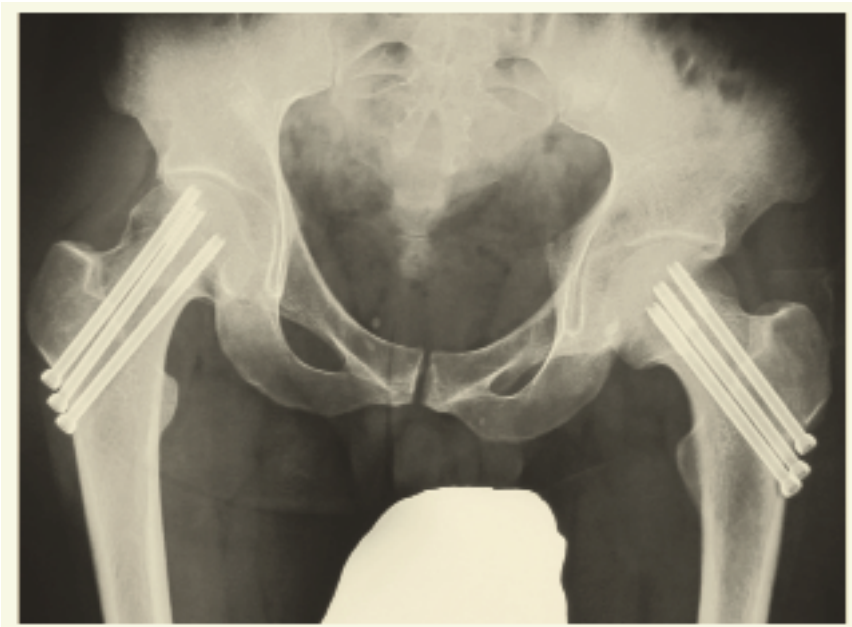

Fig. 4: A plain radiograph of the pelvis at six months postoperatively.

remained on toe-touch weight bearing for eight weeks. After discharge, he was monitored closely for six months before being allowed full activity. Two years postoperatively, he performed all training activities required for combat without residual symptoms.

\section{DISCUSSION}

The first recorded stress fracture involving the femoral neck was described by Blecher in 1905 (1). Since then, several reports have been published in young military personnel and in the older adult population (2-5). Bilateral femoral neck stress fractures in the healthy young population are extremely rare, with only two cases presented in the literature $(6,7)$.

The most common complaint is pain in the hip region on weight bearing, often accompanied by a limp. Although the diagnosis is considered in a military recruit with unilateral moderate or severe hip pain, it is not easy to diagnose when the patient has mild pain, especially in both hips, with no apparent fracture line on radiographs.
Physical examination revealed tenderness to palpation over the anterior aspect of the hip. Pain was present at the extremes of hip motion, especially flexion and internal rotation. But these may also be observed in muscle and ligament injury. Although radiographic examination usually provides the ultimate confirmation for the diagnosis, a faint fracture line can sometimes be missed. Additionally, confirmation of the fracture is impossible when the fracture line is not visible on the initial radiographs. In this case, MRI clearly demonstrated a fracture line with bone marrow oedema, leading to the definitive diagnosis. The bone scans have traditionally been considered as the standard diagnostic modality. However, false-negative results have been reported and their specificity remains inferior to that of MRI (8).

For the treatment choice, conservative or surgical, we selected surgery according to the report by Blickenstaff and Morris (4). Because of the clear fracture line on MRI, this patient under-went internal fixation with cannulated screws, yielding opti-mal final result.

To our knowledge, bilateral femoral neck fractures occurring simultaneously in a young adult with no known medical conditions have not been previously reported. Although rare in both hips, bilateral femoral neck fractures should be included in the differential diagnosis of bilateral hip pain that is exacerbated by activity.

\section{REFERENCES}

1. Blecher A. Uber den Einfluss des Parademarsches auf die Entstehung der Fussgeschwulst. Med Klin 1905; 1: 305-6.

2. Kaltsas D. Stress fractures of the femoral neck in young adults. J Bone Joint Surg 1936; 3B: 511-22.

3. Ernst J. Stress fracture of the neck of the femur. J Trauma 1964; 4: 7183.

4. Blickenstaff LD, Morris JM. Fatigue fracture of the femoral neck. J Bone Joint Surg 1966; 48A: 1031-47.

5. Bargen JH, Tilson DH, Bridgeford O. Prevention of displaced fatigue fracture of the femur. J Bone Joint Surg 1971; 53A: 1115-7.

6. Bailie DS, Lamprecht DO. Bilateral femoral neck stress fractures in an adolescent male runner. Am J Sports Med 2001; 29: 811-3.

7. Romero AN, Kohart SR. 19-year-old male adolescent with bilateral femoral neck stress fractures: a case report. Mil Med 2008; 173: 711-3.

8. Keene JS, Lash EG. Negative bone scan in a femoral neck stress fracture: a case report. Am J Sports Med 1992; 20: 234-6. 